\title{
(3) \\ Магнитные сорбенты на основе химически модифицированных кремнеземов: получение и свойства
}

\author{
Карсакова Ю.В., Тихомирова Т.И. \\ Московский государственный университет им. М.В. Ломоносова, Москва \\ Поступила в редакцию 1.10.2018 г.
}

DOI: https://doi.org/10.17308/sorpchrom.2018.18/612

Предложен способ получения магнитных сорбентов на основе кремнеземов, химически модифицированных группами иминодиуксусной кислоты (ХМК-ИДК) и гексадецильными группами (ХМК-С16), основанный на извлечении наночастиц магнетита из растворов метанола. Установлено, что сорбенты, модифицированные магнетитом, сохраняют свойства, характерные для исходных ХМК, и могут быть использованы для извлечения элементов и анионного красителя. магнетита.

Ключевые слова: сорбция, химически модифицированный кремнезем, наночастицы

\section{Magnetic adsorbent based on chemically modified silica: preparation and properties}

\author{
Karsakova I.V., Tikhomirova T.I. \\ Lomonosov Moscow State University, Department of Chemistry, Moscow
}

\begin{abstract}
Magnetite $\left(\mathrm{Fe}_{3} \mathrm{O}_{4}\right)$ nanoparticles sorbtion from methanol solutions in its concentration equal to 5.5 $\mathrm{mg} / \mathrm{cm}^{3}$ for magnetic sorbents obtaining on the basis of commercially available chemically derivatized silica (CDS) is proposed. Silica chemically modified by iminodiacetic acid groups (CDS-IDA) and silica modified by hexadecile groups $\left(\mathrm{CMS}-\mathrm{C}_{16}\right)$ were used as original sorbents. It is found that magnetic sorbent CDS$\mathrm{IDA} / \mathrm{Fe}_{3} \mathrm{O}_{4}$ synthesized in optimal conditions has the same sorption ability towards $\mathrm{Cu}^{2+}$ ions as an original sorbent. Copper sorption percentage in the optimal $\mathrm{pH}$ range of 2-6 is equal to $60-70 \%$, and diffuse reflectance spectra of these sorbents have an absorption band at 680-720 nm.

Sorption of anionic synthetic dye "Solid green" on magnetic sorbents obtained on the basis of CDS$\mathrm{C}_{16}$ with the different matrix structure characteristics is investigated (pore size 50, 25, 10 and $6 \mathrm{~nm}$ ). It was preliminary found that the settling time of adsorption equilibrium on magnetic sorbents was $30 \mathrm{~min}$. It is shown that properties of synthesized magnetic sorbents depend on original CDS pore size. It was found that effectivity of dye extraction on the magnetic sorbents $\mathrm{CDS}-\mathrm{C}_{16} / \mathrm{Fe}_{3} \mathrm{O}_{4}$ (degree of extraction 92\%) is equal to effectivity on original sorbents with $10-50 \mathrm{~nm}$ pore size. Decrease of pore size to $6 \mathrm{~nm}$ leads to decrease of extraction extent from $74 \%$ down to $30 \%$ on the magnetic sorbent in comparison with the original one. Probably, because of small pore size the magnetic particles can occupy adsorption sites, decreasing effectiveness of the dye extraction.
\end{abstract}

Keywords: sorption, chemically modified silica, magnetite nanoparticles

\section{Введение}

Подготовка проб является решающим этапом для проведения химического, анализа. В последние годы применение наноматериалов в качестве сорбентов для 
выделения и концентрирования различных соединений привлекает внимание исследователей. Среди прочих выделяются магнитные наноматериалы, преимущественно магнетит $\left(\mathrm{Fe}_{3} \mathrm{O}_{4}\right)$, и магнитные сорбенты на их основе, бесспорным достоинством которых является возможность управлять их перемещением с помощью внешнего постоянного магнитного поля. Использование этих сорбентов в методе магнитной твердофазной экстракции (МТФЭ) преодолевает многие проблемы проведения сорбции таких как, например, уплотнение колонок, упрощает разделение фаз, которое можно легко выполнить, применив внешнее магнитное поле [1]. Кроме того, применение магнитных наночастиц (МНЧ) обладает рядом достоинств в аналитических исследованиях, поскольку на магнитные взаимодействия не влияют такие факторы как $\mathrm{pH}$, концентрация или поверхностные заряды аналитов.

В настоящее время синтезировано много магнитных сорбентов, которые можно разделить на две большие группы. К первой группе относятся сорбенты со структурой ядро-оболочка, которые получают нековалентной или ковалентной иммобилизацией на поверхности предварительно синтезированных наночастиц оксидов железа различных неорганических или органических соединений. Ко второй группе принадлежат нанокомпозитные углеродные или полимерные материалы, содержащие инкапсулированные магнитные наночастицы [2, 3].

Второй способ получения нанокомпозитных материалов существенно проще и заключается во внедрении наночастиц оксидов железа в немагнитные матрицы. Этот способ осуществляется путем сорбции МНЧ или обработкой сорбентов растворами солей железа (II, III) и последующем формировании МНЧ на их поверхности. Полученные таким образом сорбционные материалы в последнее время находят все более широкое применение в качестве сорбентов в методе МТФЭ. Они сочетают сорбционные свойства исходных материалов с возможностью управлять процессом сорбции при помощи магнитного поля. В настоящее время известны и успешно применяются в аналитической практике такие сорбенты на основе углерода [4] и органополимерных матриц, в частности сверхсшитого полистирола [5].

Представляет интерес изучить возможность получения магнитных сорбентов на основе химически модифицированных кремнеземов (ХМК) - коммерчески доступных сорбентов, которые прекрасно зарекомендовали себя для проведения сорбционного концентрирования органических соединений и элементов. Модифицирование этих сорбентов магнитными наночастицами оксидов железа может придать им новые свойства и расширить область их применения для разработки новых схем пробоподготовки различных объектов. Работы по внедрению магнитных наночастиц оксида железа в кремнеземную матрицу, в основном касаются только получения новых катализаторов.

\section{Эксперимент}

Реагенты. Для синтеза наночастиц $\mathrm{Fe}_{3} \mathrm{O}_{4}$ использовали $\mathrm{FeCl}_{3} \cdot 6 \mathrm{H}_{2} \mathrm{O}$ (х.ч.), $\mathrm{FeSO}_{4} \cdot\left(\mathrm{NH}_{4}\right)_{2} \mathrm{SO}_{4} \cdot 6 \mathrm{H}_{2} \mathrm{O}$ (х.ч.) и $\mathrm{NH}_{3}$ (х.ч.). В качестве исходных материалов для получения магнитных сорбентов использовали образцы кремнеземных сорбентов, химически модифицированных гексадецильными группами: ХМК- $\mathrm{C}_{16}-500, \mathrm{XMK} \mathrm{C}_{16}-$ 250 , ХМК- $\mathrm{C}_{16}-100, \mathrm{XMK}_{16}-60$, Силохром С-120, а также группами иминодиуксусной кислоты ХМК-ИДК-500 («БиоХимМак СТ», Россия) и ХМК-ИДК-100 («Merck», Германия). Характеристики сорбентов приведены в табл.1.

Для оценки свойств новых сорбентов использовали: раствор анионного красителя трифенилметанового ряда «Зеленый прочный» чистоты $\geq 85 \%$ (SigmaALDRICH), приготовленный растворением точной навески реагента в воде (c=1.0

Карсакова и др. / Сорбционные и хроматографические процессы. 2018. Т. 18. № 6 


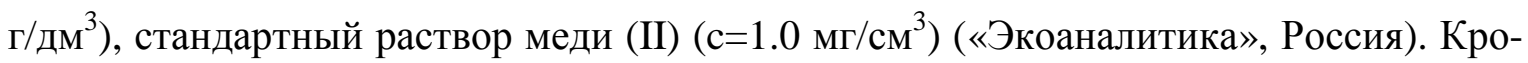
ме того, в работе использовали соляную кислоту (х.ч.), раствор гидроксида натрия (ч.д.а.), метанол (х.ч.), ацетонитрил (х.ч.), этанол (х.ч.), изопропанол (ос.ч.), ацетон (ос.ч.).

Таблица 1. Характеристики используемых сорбентов

\begin{tabular}{|c|c|c|c|c|}
\hline Сорбент & Диаметр пор, нм & $\begin{array}{c}\text { Размер частиц, } \\
\text { мкм }\end{array}$ & $\mathrm{S}_{\text {уд, }}{ }^{2} / \Gamma$ & Содержание С, \% \\
\hline Силохром С-120 & 50 & $0.315-0.5$ & 120 & - \\
\hline ХМК-ИДК-500 & 50 & $200-350$ & 120 & - \\
\hline ХМК-ИДК-100 & 10 & $60-200$ & 300 & - \\
\hline ХМК-С $_{16}-500$ & 50 & $100-200$ & 80 & 4.8 \\
\hline ХМК-С $_{16}-250$ & 25 & $100-200$ & 120 & 5.5 \\
\hline ХМК-С $_{16}-100$ & 10 & $63-200$ & 300 & 16.5 \\
\hline ХМК-С $_{16}-60$ & 6 & $0.3-100$ & 500 & 19.4 \\
\hline
\end{tabular}

Аппаратура. Спектры диффузного отражения в видимой области регистрировали на мини-спектрофотометре «Eye-One Pro» (X-Rite). Оптические плотности растворов регистрировали на спектрофотометре СФ-103 («Аквилон», Россия), в диапазоне от 200 до 700 нм, в стеклянных кюветах (l=1cм), с промером базовой линии по растворителю. Значения $\mathrm{pH}$ растворов контролировали на $\mathrm{pH}$-метре-иономере «Эксперт 001» («Эконикс-Эксперт», Россия). Магнитную ТФЭ проводили на электромеханическом шейкере Экрос-6500 («Экросхим», Россия). Магнитный сорбент отделяли от раствора, используя $\mathrm{Nd}-\mathrm{Fe}-\mathrm{B}$ магнит $(20 \times 20 \times 20$ мм $)$.

Наноразмерные частицы $\mathrm{Fe}_{3} \mathrm{O}_{4}$ получали путем химического осаждения по модифицированной методике Массара (метод 1) [6]. Концентрация $\mathrm{Fe}_{3} \mathrm{O}_{4}$ составила

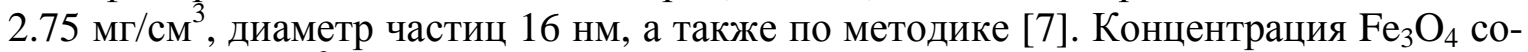
ставила $1.2 \mathrm{мг} / \mathrm{cm}^{3}$, диаметр частиц 10 нм (метод 2).

Методика получения сорбентов, модифицированных магнетитом. Магнитные сорбенты на основе коммерчески доступных образцов ХМК получали в два этапа: сначала синтезировали наноразмерные частицы магнетита (МНЧ), а затем проводили их сорбцию на кремнеземных сорбентах. Свежеполученный осадок $\mathrm{Fe}_{3} \mathrm{O}_{4}$ отделяли магнитной сепарацией от раствора, промывали несколько раз дистиллированной водой до $\mathrm{pH}$ 6-7, диспергировали в $5.0 \mathrm{~cm}^{3}$ растворителя и добавляли 0.10 г кремнеземного сорбента. Затем перемешивали на электромеханическом шейкере в течение 20 мин. Полученный магнитный сорбент отделяли декантацией, промывали небольшой порцией растворителя, фильтровали и высушивали на воздухе. Сорбенты представляли собой порошки коричневого цвета.

Методика проведения сорбции меди (II). В градуированные пробирки емкостью $15 \mathrm{~cm}^{3}$ вносили $1.0 \mathrm{~cm}^{3}$ раствора меди $\left(5 \cdot 10^{-3} \mathrm{r} /\right.$ дм $\left.^{3}\right), 0.1 \mathrm{M}$ раствор $\mathrm{HCl}$ для создания необходимого значения $\mathrm{pH}$ и разбавляли смесь водой до $10.0 \mathrm{~cm}^{3}$. Затем в полученный раствор помещали 0.10 г сорбента и встряхивали на вибросмесителе в течение времени необходимого для установления сорбционного равновесия. Содержание меди определяли спектрофотометрически с использованием реагента пикраминэпсилон [8]. В случае магнитных ХМК, сорбент отделяли от водной фазы с помощью магнитной сепарации. Содержание в фазе сорбента рассчитывали по разности между исходной концентрацией и равновесной концентрацией в водной фазе.

Методика проведения сорбции красителя. В градуированные пробирки емкостью $15 \mathrm{~cm}^{3}$ вносили $1.0 \mathrm{~cm}^{3}$ раствора красителя $\left(0.1\right.$ г/дм $\left.^{3}\right), 1.0 \mathrm{~cm}^{3} 0.1 \mathrm{M}$ раствора $\mathrm{HCl}$ для создания необходимого значения $\mathrm{pH}$ и разбавляли смесь водой до $10.0 \mathrm{~cm}^{3}$. 
Измеряли оптическую плотность раствора до сорбции. Затем в полученный раствор помещали 0.07 г сорбента и встряхивали на вибросмесителе в течение времени, необходимого для установления сорбционного равновесия.

Содержание красителя в водной фазе определяли спектрофотометрически по собственному поглощению при $\lambda=627$ нм, содержание в фазе сорбента рассчитывали по разности между исходной концентрацией и равновесной концентрацией в водной фазе. В случае с магнитными сорбентами сорбент отделяли от водной фазы с помощью магнитной сепарации.

\section{Обсуждение результатов}

Оптимизация условий модифицирования ХМК магнетитом.

Выбор растворителя. Одним из основных факторов, влияющих на сорбцию МНЧ, является природа растворителя. Для выбора растворителя, обеспечивающего максимальное извлечение $\mathrm{Fe}_{3} \mathrm{O}_{4}$ в матрицу кремнезема, сорбцию проводили из воды, ацетонитрила и метанола. Для этого использовали $1.0 \mathrm{~cm}^{3}$ суспензии свежеосажденных наночастиц $\mathrm{Fe}_{3} \mathrm{O}_{4}$, которые диспергировали в $5.0 \mathrm{~cm}^{3}$ растворителя и перемешивали на электромеханическом шейкере с 0.05 г сорбента в течение 20 мин. Контроль содержания МНЧ в фазе сорбента проводили с использованием спектроскопии диффузного отражения.

Предварительное изучение проводили на кремнеземе, химически модифицированном группами иминодиуксусной кислоты, ХМК-ИДК-500 и чистом кремнеземе Силохром С-120, имеющими одинаковые структурные характеристики. На рис. 1 приведены спектры диффузного отражения сорбентов, модифицированных МНЧ. Значения функции Гуревича-Кубелки-Мунка (F) при 400 нм, рассчитанные по формуле $\mathrm{F}=(1-\mathrm{R})^{2} / 2 \mathrm{R}$, где $\mathrm{R}$ измеренный коэффициент диффузного отражения при длине волны минимального отражения (максимального поглощения) [9] приведены в табл.2. На основании полученных данных можно сделать вывод, что сорбция МНЧ в метаноле выше по сравнению с сорбцией в воде (при использовании ацетонитрила сорбция практически отсутствовала). Присутствие групп ИДК на поверхности кремнезема не влияет на извлечение МНЧ, так как значение функции F практически одинаково для чистого кремнезема и ХМК-ИДК-500. На основании этих предварительных исследований для получения магнитных сорбентов в качестве растворителя был выбран метанол.
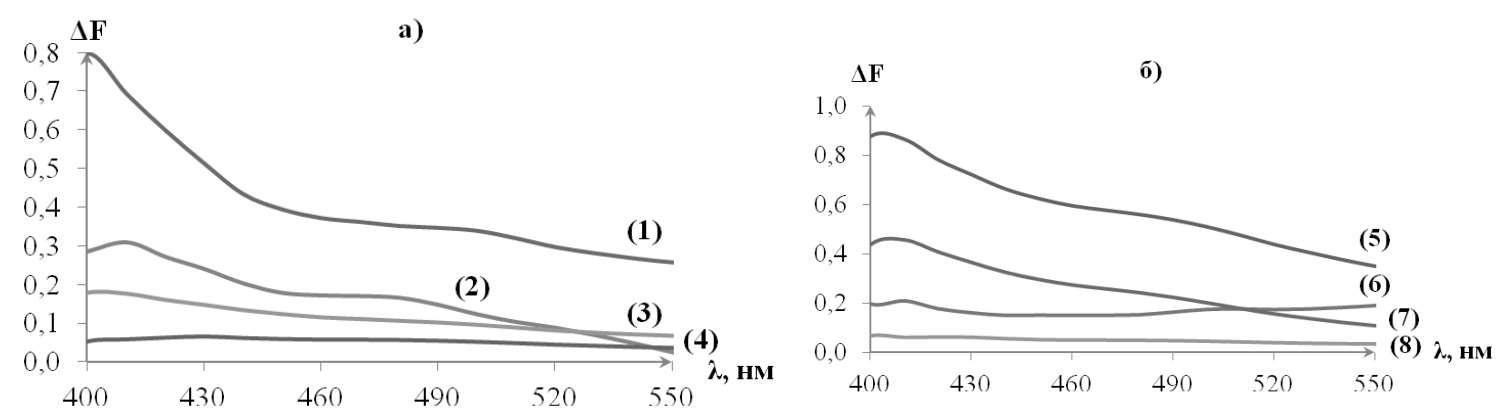

Рис. 1. Спектры диффузного отражения магнитных сорбентов на основе:

a) Силохром C-120; б) ИДК-500 ( $\mathrm{m}_{\text {сорб. }}=0.05 \mathrm{r}, \mathrm{V}_{\mathrm{мнч}}=1.0 \mathrm{~cm}^{3}, \mathrm{t}=20$ мин):

1 - Силохром C-120/ $\mathrm{Fe}_{3} \mathrm{O}_{4}-\mathrm{MeOH}$ (метод 1); 2 - Силохром C-120/ $\mathrm{Fe}_{3} \mathrm{O}_{4}-\mathrm{H}_{2} \mathrm{O}$ (метод 1);

3 - Силохром C-120/ $\mathrm{Fe}_{3} \mathrm{O}_{4}-\mathrm{MeOH}$ (метод 2); 4 - Силохром C-120/ $\mathrm{Fe}_{3} \mathrm{O}_{4}-\mathrm{H}_{2} \mathrm{O}$ (метод 2);

5 - ХМК-ИДК-500/ $\mathrm{Fe}_{3} \mathrm{O}_{4}-\mathrm{MeOH}$ (метод 1); 6 - ХМК-ИДК-500/ $/ \mathrm{Fe}_{3} \mathrm{O}_{4}-\mathrm{H}_{2} \mathrm{O}$ (метод 1);

7 - ХМК-ИДК-500/ $\mathrm{Fe}_{3} \mathrm{O}_{4}-\mathrm{MeOH}$ (метод 2); 8 - ХМК-ИДК-500/ $\mathrm{Fe}_{3} \mathrm{O}_{4}-\mathrm{H}_{2} \mathrm{O}$ (метод 2)

Карсакова и др. / Сорбционные и хроматографические процессы. 2018. Т. 18. № 6 
Таблица 2. Значение функции $\Delta \mathrm{F}(\lambda=400$ нм) сорбентов Силохром С-120 и ХМКИДК-500 при сорбции МНЧ в воде и в метаноле $\left(\mathrm{m}_{\text {сорб. }}=0.05 \Gamma, \mathrm{V}=5.0 \mathrm{~cm}^{3}, \mathrm{t}=20\right.$ мин $)$

\begin{tabular}{|c|c|c|c|}
\hline \multirow{2}{*}{ Сорбент } & \multirow{2}{*}{ Растворитель } & \multicolumn{2}{|c|}{$\Delta \mathrm{F}(\mathrm{R})$} \\
\cline { 2 - 4 } & & Метод 1 & Метод 2 \\
\hline \multirow{2}{*}{ Силохром С-120 } & $\mathrm{H}_{2} \mathrm{O}$ & 0.3098 & 0.0669 \\
\cline { 2 - 4 } & $\mathrm{CH}_{3} \mathrm{OH}$ & 0.7973 & 0.1801 \\
\hline \multirow{2}{*}{ ХМК-ИДК-500 } & $\mathrm{H}_{2} \mathrm{O}$ & 0.2091 & 0.0679 \\
\cline { 2 - 4 } & $\mathrm{CH}_{3} \mathrm{OH}$ & 0.8787 & 0.4563 \\
\hline
\end{tabular}

Зависимость сорбции МНЧ от их концентрации. Изучена сорбция МНЧ на сорбентах на основе кремнезема от их концентрации в растворе метанола (рис.2). Сорбцию проводили из $5.0 \mathrm{~cm}^{3}$ метанола.
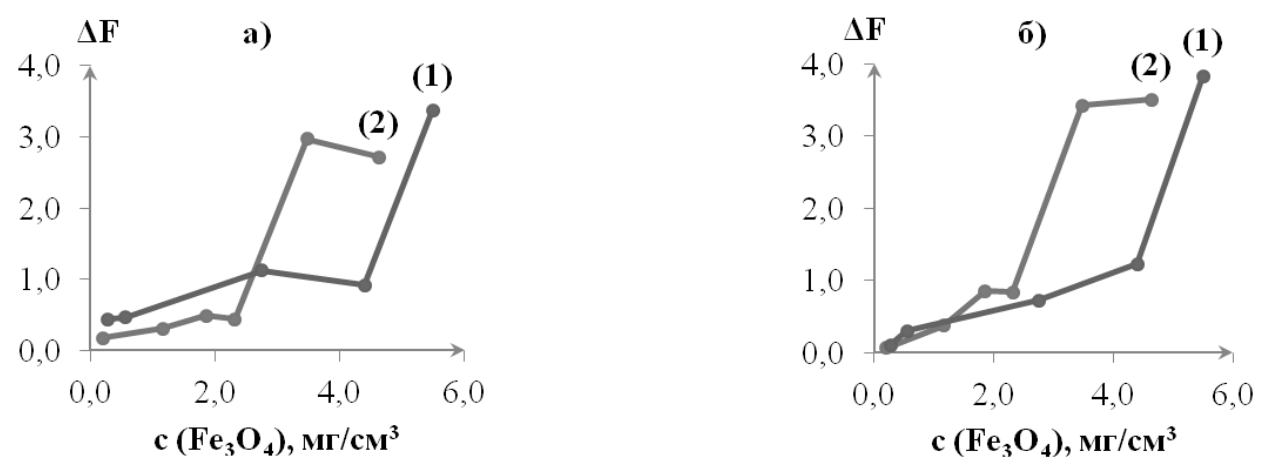

Рис. 2. Зависимость функции $\mathrm{F}(\lambda=400$ нм) а) Силохром C-120,

б) ХМК-ИДК-500 от концентрации МНЧ, полученных по методу 1 (1) и по методу 2 (2) (m сорб. $=0.10$ г, $\mathrm{V}=5.0 \mathrm{~cm}^{3}, \mathrm{t}=20$ мин)

Наибольшее значение $\Delta \mathrm{F}$, где $\Delta \mathrm{F}$ - разница между значением $\mathrm{F}$ магнитного сорбента и исходным сорбентом, наблюдается как на чистом кремнеземе, так и на ХМК-ИДК при концентрации МНЧ 5.5 мг/ $\mathrm{cm}^{3}$ (в метаноле), полученных по методу 1. Образцы сорбентов, полученных в этих условиях, обладают наиболее выраженными магнитными свойствами. Поэтому в дальнейшем использовали навески сорбентов массой 0.10 г и $10.0 \mathrm{~cm}^{3}$ водной суспензии МНЧ, полученных, по методу $1, \mathrm{c}$ концентрацией $2.75 \mathrm{мг} / \mathrm{cm}^{3}$, которые отделяли от раствора магнитной сепарацией и диспергировали в $5.0 \mathrm{~cm}^{3}$ метанола.

Сорбционные свойства ХМК, модифицированных магнетитом. Сорбция МНЧ может изменять свойства исходных сорбентов, например, блокируя функциональные группы. Наиболее часто в аналитической практике используют ХМК, содержащие привитые группы иминодиуксусной кислоты, для концентрирования ионов металлов и ХМК, модифицированные гексадецильными группами, для концентрирования органических соединений, свойства которых хорошо изучены [10].

Сорбция меди на сорбенте ХМК-ИДК-500/Fe ${ }_{3} \underline{\mathrm{O}}_{4}$. Проведено сравнение сорбции меди (II) на ХМК-ИДК-500 и на том же сорбенте, модифицированном МНЧ (ХМК-ИДК-500/ $\mathrm{Fe}_{3} \mathrm{O}_{4}$ ). Поскольку возможна сорбция ионов меди (II) на самом магнетите, также изучена их сорбции на кремнеземе, модифицированном МНЧ (Силохром $\mathrm{C}-120 / \mathrm{Fe}_{3} \mathrm{O}_{4}$ ). Сорбцию проводили при $\mathrm{pH} 3$, концентрация меди $5 \cdot 10^{-3}$ мг $/ \mathrm{cm}^{3}$.

В спектре диффузного отражения сорбента Силохром С-120/ $\mathrm{Fe}_{3} \mathrm{O}_{4}$ и Силохром С-120 отсутствует полоса поглощения в области 680-720 нм, характерная для ионов $\mathrm{Cu}^{2+}$, что свидетельствует об отсутствии сорбции меди на этих сорбентах. Спектры диффузного отражения сорбентов ХМК-ИДК-500/Fe ${ }_{3} \mathrm{O}_{4}$ и ХМК-ИДК-500 характеризуются наличием полосы поглощения области 680-720 нм. Определена 
степень извлечения меди на этих сорбентах в интервале $\mathrm{pH}$ 3-6. Для этого проводили определение меди после установления сорбционного равновесия в водной фазе. Установлено, что степень извлечения практически одинакова и составляет 60-70\%.

Таким образом, установлено, что модифицирование ХМК-ИДК-500 МНЧ не влияет на сорбцию меди (II) и, следовательно, не изменяет свойства привитых функциональных групп на поверхности сорбента.

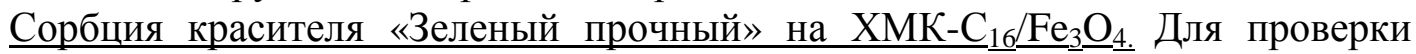
сорбционных свойств ХМК-С 16 , модифицированных МНЧ, использовали в качестве модельного эксперимента сорбцию красителя «Зеленый прочный», поскольку согласно литературным данным этот краситель эффективно извлекается на ХМК-С 16 в широком диапазоне $\mathrm{pH}$ [11]. Исходной матрицей служили образцы кремнеземных сорбентов, модифицированных гексадецильными группами, с различными структурными характеристиками: ХМК- $\mathrm{C}_{16}-500, \mathrm{XMK}^{-} \mathrm{C}_{16}-250, \mathrm{XMK}-\mathrm{C}_{16}-100$ и XМК-С ${ }_{16}-$ 60 (табл.1).

На начальном этапе исследования проведено сравнение сорбционных свойств сорбентов ХМК-С $16-500$ и чистого кремнезема Силохром С-120 и тех же сорбентов, модифицированных МНЧ. Установлено, что степень извлечения ЗП не отличается на сорбентах ХМК- $\mathrm{C}_{16}$ и ХМК- $\mathrm{C}_{16} / \mathrm{Fe}_{3} \mathrm{O}_{4}$ и составляет $90 \%$, степень извлечения на Силохром С-120 и Силохром $\mathrm{C}-120 / \mathrm{Fe}_{3} \mathrm{O}_{4}$ не превышает $37.8 \%$ (табл.3). Полученные данные подтверждают, что Силохром C-120/Fe $\mathrm{O}_{4}$ и Силохром C-120 слабо сорбируют краситель «Зеленый прочный». Модифицирование сорбента ХMК-С $\mathrm{X}_{16}-500$ МНЧ не влияет на его сорбционные свойства.

Таблица 3. Степень сорбции ЗП ( $\mathrm{R}, \%)$ на ХМК- $\mathrm{C}_{16}-500$ и Силохром $\mathrm{C}-120$ $\left(\mathrm{m}_{\text {сорб }}=0.07\right.$ г, $\mathrm{C}_{3 \Pi}=5 \cdot 10^{-3}$ г/дм $\left.{ }^{3}, \mathrm{~V}=10.0 \mathrm{~cm}^{3}\right)$

\begin{tabular}{|c|c|}
\hline Сорбент & $\mathrm{R}, \%$ \\
\hline ХМК- $\mathrm{C}_{16}-500$ & 93.6 \\
\hline ХМК- $\mathrm{C}_{16}-500 / \mathrm{Fe}_{3} \mathrm{O}_{4}$ & 90.1 \\
\hline Силохром C-120 & 37.8 \\
\hline Силохром $\mathrm{C}-120 / \mathrm{Fe}_{3} \mathrm{O}_{4}$ & 23.6 \\
\hline
\end{tabular}

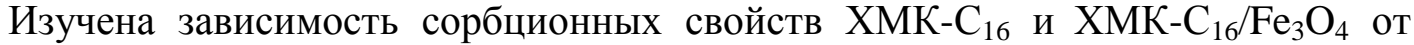
размера пор исходного сорбента. На рис.3 приведены зависимости значений степеней извлечения от времени контакта фаз: на ХМК-С $16-250$ сорбционное равновесие устанавливается за 30 минут, для ХМК-С ${ }_{16}-100$ за 45 минут, для сорбента ХМК-С $16^{-}$ 60 нм потребовалось больше времени для достижения постоянного значения степени извлечения. В последнем случае сорбционное равновесие устанавливается медленнее вследствие маленького размера пор сорбента.
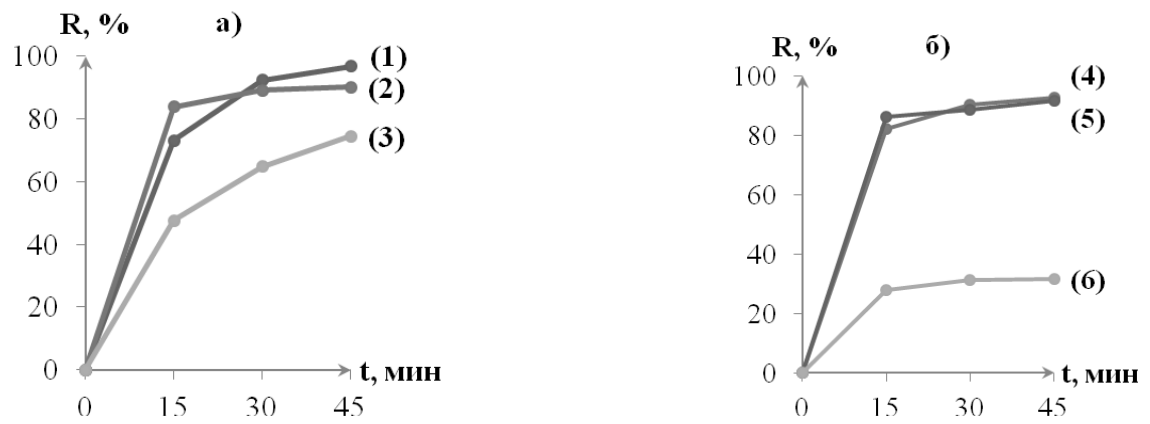

Рис. 3. Зависимость степени извлечения (R,\%) 3П на: a) XMК-C 16 :

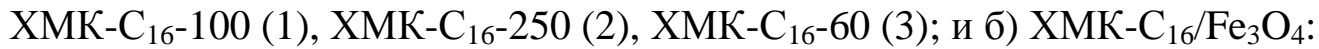

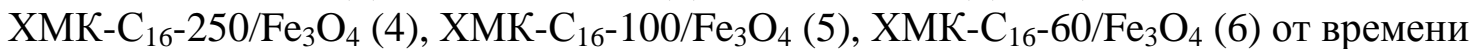
контакта фаз ( $\mathrm{m}_{\text {сорб. }}=0.07$ г, $\mathrm{C}_{3 \Pi}=0.01 \mathrm{r}^{2}$ дм $\left.^{3}, \mathrm{~V}=10.0 \mathrm{~cm}^{3}\right)$ 
В случае сорбции на магнитных сорбентах, сорбционное равновесие устанавливалось за 30 минут (рис. 3б). Установлено, что степень сорбции ЗП зависит от размера пор сорбента. Сорбция на ХМК-С $16-60$ (размер пор - 6 нм) проходит с меньшим процентом извлечения и составляет $74 \%$, сорбция на $\mathrm{XMK-C} 16-250$ (размер пор - 25 нм) и ХМК-С 16 -100 (размер пор 10 нм) с большим процентом извлечения -90.3 и $96.9 \%$ соответственно.

Таблица 4. Степень извлечения (R,\%) ЗП на ХМК-C 16 и $\mathrm{XMK}_{-16} \mathrm{C}_{16} / \mathrm{Fe}_{3} \mathrm{O}_{4}\left(\mathrm{~m}_{\text {сорб. }}=0.07\right.$ $г, \mathrm{C}_{3 \Pi}=0.01$ г/дм ${ }^{3}, \mathrm{~V}=10.0 \mathrm{~cm}^{3}, \mathrm{t}=45 \mathrm{мин)}$

\begin{tabular}{|c|c|}
\hline Сорбент & $\mathrm{R}, \%$ \\
\hline $\mathrm{XMK}-\mathrm{C}_{16}-250$ & 90.3 \\
\hline $\mathrm{XMK}_{1}-\mathrm{C}_{16}-250 / \mathrm{Fe}_{3} \mathrm{O}_{4}$ & 92.7 \\
\hline $\mathrm{XMK}-\mathrm{C}_{16}-100$ & 96.9 \\
\hline $\mathrm{XMK}-\mathrm{C}_{16}-100 / \mathrm{Fe}_{3} \mathrm{O}_{4}$ & 91.7 \\
\hline $\mathrm{XMK}-\mathrm{C}_{16}-60$ & 74.5 \\
\hline $\mathrm{XMK}-\mathrm{C}_{16}-60 / \mathrm{Fe}_{3} \mathrm{O}_{4}$ & 31.5 \\
\hline
\end{tabular}

При использовании сорбентов, модифицированных магнетитом, сорбция ЗП практически не изменяется в случае, если диаметр пор матрицы более $10 \mathrm{Hм}$

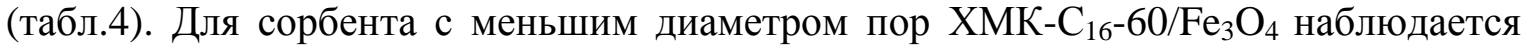
значительно меньший процент извлечения по сравнению с исходным сорбентом. Вероятно, вследствие малого размера пор, магнитные частицы могут блокировать сорбционные центры, понижая эффективность извлечения.

\section{Заключение}

Таким образом, установлено, что магнитные сорбенты на основе химически модифицированных кремнеземов могут быть получены путем сорбции наночастиц магнетита из метанола. Показано, что сорбционные свойства полученных сорбентов не отличаются от исходных ХМК, для которых диаметр пор не менее 10 нм.

\section{Список литературы}

1. Giakisikli G., Anthemidis A.N. // Anal. Chim. Acta. 2013. Vol. 789. pp. 1-16. DOI: 10.1016/j.aca.2013.04.021.

2. Толмачева В.В., Апяри В.В., Кочук Е.В., Дмитриенко С.Г. // Журн. аналит. химии. 2016. T. 71. № 4. C. 339-356. DOI: 10.7868/S0044450216040071.

3. Xie L., Jiang R., Zhu F., Liu H., Ouyang G. // J. Anal Bioanal Chem. 2014. Vol. 406. pp. 377-399. DOI: 10.1007/s00216-013-7302-6.

4. Herrera-Herrera A.V., Hernández-Borges J., Afonso M.M., Palenzuela J.A. et al. // Talanta. 2013. Vol. 116. pp. 695-703. DOI: 10.1016/j.talanta.2013.07.060.

5. Pastukhov A.V., Davankov V.A, Volkov V.V., Amarantov S.V. et al. // J. Polym. Res. 2014. Vol. 21. pp. 406-416. DOI: 10.1007/s10965-014-0406-7.
6. Толмачева В.В., Апяри В.В., Ибрагимова Б.Н., Кочук Е.В. и др. // Журн. аналит. химии. 2015. Т. 70. № 11. С. 1149-1157. DOI: 10.7868/S004445021511016X.

7. Петракова А.В., Урусов А. Е., Костенко С.Н., Придворова С.М. и др. // Научное обозрение. Химические науки. 2014. № 1. С. 2829.

8. Подчайнова В.И., Симонова Л.Н. Аналитическая химия элементов. Медь. М. Наука. 1990. $278 \mathrm{c}$.

9. Кортюм Г., Браун В., Герцог Г. // Усnехи физ. наук. 1965. T. 85. C. 365-379. DOI: 10.3367/UFNr.0085.196502f.0365.

10. Лисичкин Г.В., Фадеев А.Ю., Сердан А.А., Нестеренко П.Н. и др. Химия привитых поверхностных соединений. М.: Физматлит. 2003. 592 с. 
11. Tikhomirova T.I., Ramazanova G.R., 351-355.

DOI:

Apyari V.V. // Food Chem. 2017. Vol. 221. pp. 10.1016/j.foodchem.2016.10.042.

\section{References}

1. Giakisikli G., Anthemidis A.N., Anal. 1313-1321.

DOI:

Chim. Acta, 2013, Vol. 789, pp. 1-16. DOI: 10.1134/S1061934815110155.

10.1016/j.aca.2013.04.021.

2. Tolmacheva V.V., Apyari V.V., Kochuk

E.V., Dmitrienko S.G., J. Analyt. Chem., 2016,

Vol. 71, No 4, pp. 321-348. DOI: 10.1134/S1061934816040079.

3. Xie L., Jiang R., Zhu F., Liu H. Et al., J. Anal. Bioanal. Chem., 2014, Vol. 406, pp. 377399. DOI: 10.1007/s00216-013-7302-6.

4. Herrera-Herrera A.V., Hernández-Borges J., Afonso M.M., Palenzuela J.A. et al., Talanta, 2013, Vol. 116, pp. 695-703. DOI: 10.1016/j.talanta.2013.07.060.

5. Pastukhov A.V., Davankov V.A, Volkov V.V., Amarantov S.V. et al., J. Polym. Res., 2014, Vol. 21, pp. 406-416. DOI: 10.1007/s10965-014-0406-7.

6. Tolmacheva V.V., Apyari V.V., Ibragimova B.N. et al., J. Analyt. Chem., 2015, Vol. 70, pp.

Тихомирова Татьяна Ивановна - ведущий научный сотрудник кафедры аналитической химии, д.х.н., Московский государственный университет им. М.В.Ломоносова, Химический факультет, Москва

Карсакова Юлия Валерьевна - аспирант кафедры аналитической химии, инженер первой категории кафедры аналитической химии Московского государственного университета, Москва

7. Petrakova A.V., Urusov A.E., Kostenko S.N., Pridvorova S.M. et al., Scientific review. Chemical Sciences, 2014, No 1, pp. 28-29.

8. Podchaynova V.I., Simonova L.N. Analytical chemistry of elements. Copper. M., Nauka Publ., 1990, 278 p.

9. Kortyum G., Braun V., Gertsog G., Usp. Fiz. Nauk, 1965, Vol. 85, pp. 365-379. DOI: 10.3367/UFNr.0085.196502f.0365.

10. Lisichkin G.V., Fadeev A.Y., Cerdan A.A., Nesterenko P.N. et al., Chemistry of Surface Grafted Compounds. M.: Fizmatlit., 2003, $592 \mathrm{p}$.

11. Tikhomirova T.I., Ramazanova G.R., Apyari V.V., Food Chem., 2017, Vol. 221, pp. 351-355.

DOI:

10.1016/j.foodchem.2016.10.042.

Tikhomirova Tatyana I. - Lead Researcher, grand Ph.D (chemistry), department of analytical chemistry, Lomonosov Moscow State University, Chemistry Department, Moscow. E-mail: tikhomirova-tatyana@yandex.ru.

Karsakova Iuliia V. - the postgraduate student of department of analytical chemistry, engineer of department of analytical chemistry, Lomonosov Moscow State University, Chemistry Department, Moscow, e-mail: julia.karsakova@yandex.ru. 